\title{
Observed and modeled near-wake flow behind a solitary tree
}

Dellwik, Ebba; van der Laan, Paul; Angelou, Nikolas; Mann, Jakob; Sogachev, Andrey

Published in:

Agricultural and Forest Meteorology

Link to article, DOI:

10.1016/j.agrformet.2018.10.015

Publication date:

2019

Document Version

Peer reviewed version

Link back to DTU Orbit

Citation (APA):

Dellwik, E., van der Laan, P., Angelou, N., Mann, J., \& Sogachev, A. (2019). Observed and modeled near-wake flow behind a solitary tree. Agricultural and Forest Meteorology, 265, 78-87.

https://doi.org/10.1016/j.agrformet.2018.10.015

\section{General rights}

Copyright and moral rights for the publications made accessible in the public portal are retained by the authors and/or other copyright owners and it is a condition of accessing publications that users recognise and abide by the legal requirements associated with these rights.

- Users may download and print one copy of any publication from the public portal for the purpose of private study or research.

- You may not further distribute the material or use it for any profit-making activity or commercial gain

- You may freely distribute the URL identifying the publication in the public portal 


\title{
Observed and modeled near-wake flow behind a solitary tree
}

\author{
E. Dellwik*, M.P. van der Laan, N. Angelou, J. Mann, A. Sogachev \\ Technical University of Denmark, Wind Energy Department, Denmark
}

\section{A R T I CLE INFO}

\section{Keywords:}

Drag force

RANS

Terrestrial lidar scanning

Wake

Strain gauge

\begin{abstract}
A B S T R A C T
This study reports simultaneous measurements of wind at single point positions up- and downstream of a tree and a numerical experiment with the aim of quantifying the interaction of a solitary tree and the wind field. Relative to the inflow velocity, the velocity deficit in the wake of the tree showed strong seasonal dependence, with wake velocities changing between $70 \%$ and $10 \%$ of the upstream value from no-leaf winter conditions to full-leaf summer conditions. Whereas for the winter tree the turbulence intensity in the wake is everywhere reduced relative to the upwind flow, for the summer tree the turbulent intensity is markedly reduced in the inner wake, but increased in the outer wake.

For the numerical experiment, the combination of (i) a high-detail tree model, based on terrestrial lidar scanning, and (ii) observations of the total bending moment on the tree, taken from strain gauges mounted on the stem, provided the tree parameterization. By this approach, the drag coefficient is not calibrated to fit the observed wind speed in the wake, but the total observed bending moment. Mean wind speed observations in the wake of both the winter and summer tree were well reproduced by the model with mean absolute errors lower than or equal to $5 \%$ throughout the wake transect. Also the turbulence intensity in the wake were well reproduced for the summer tree, whereas it was overestimated for the winter tree. Effects of changing tree model and grid resolution are demonstrated and discussed. Based on the presented findings, we recommend to estimate the total bending moment (or drag force) on modelled trees to ensure transferability of results between different numerical setups.
\end{abstract}

\section{Introduction}

The typical European rural landscape is a heterogeneous patchwork, where large solitary trees often are placed in between the agricultural fields. The effects of such trees are challenging to correctly represent in meteorological models, because of their multi-scale species-dependent structure, yet their effect on the wind field may be important based on the capability of the trees to efficiently transfer energy from the mean wind to the turbulent scales (Patton et al., 2016). In this study, we explore how well a combination of tools adapted for the characterization of forest flow can describe the effect of a particular tree.

Air flow over the landscape is governed by the Navier-Stokes equations. Solutions to the equations are commonly provided either by using a Reynolds averaged Navier-Stokes formulation (RANS), where a stationary solution is achieved, or a Large Eddy Simulation (LES), in which the large eddies of the air flow are resolved. The presence of trees and forests in the landscape normally enters the Navier-Stokes

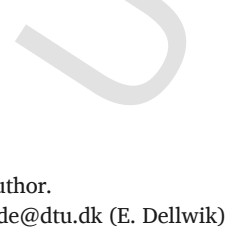

\footnotetext{
* Corresponding author.

Email address: ebde@dtu.dk (E. Dellwik)
}

equations via the force density term $F_{i}$, which accounts for the spatially averaged form and viscous drag over the canopy elements inside a volume (e.g. Finnigan, 2000):

$F_{i}=\rho C_{d} A_{\mathrm{PAD}}|U| U_{i}$,

where $\rho$ is the density of the air, $C_{d}$ is the drag coefficient, $A$ is the one-sided plant area density, $|U|$ is the magnitude of the wind vector and $U_{i}$ is the wind component in the $i=1,2,3$ direction, corresponding to the along-wind, the cross-wind and the vertical wind direction. When applying this equation to numerical modeling, $F_{i}, C_{d}$ and $U_{i}$ are volume averages over the voxels defined by the numerical grid. It is also worth emphasizing that $U_{i}$ and $C_{d}$ here represent the local or in-situ wind vector and drag coefficient, respectively, in contrast to the upwind undisturbed wind speed and the bulk $C_{d}$ as used in, for example, Rudnicki et al. (2004). For a multi-level numerical model and horizontally heterogeneous canopy, $A_{P A D}$ varies in space in all three coordinate directions.

Using the parameterization in Eq. (1), remarkable progress has been made over the last decades in modelling the wind flow over horizontally-homogeneous canopy by both RANS models (Pinard and Wilson, 
2001; Katul et al., 2004; Sogachev and Panferov, 2006; Sogachev et al., 2012a) and large-eddy simulations (LES) (Dwyer et al., 1997; Shaw and Patton, 2003; Finnigan et al., 2009). The effect of forest heterogeneities in the landscape landscape has also been studied with numerical simulations. In example, Li et al. (1990) modelled the flow over a forest edge, Wilson and Flesch (1999) modelled patches of horizontally-homogeneous forest blocks, Wang et al. (2001) reviewed the effects of shelterbelts on the wind field. Following the rapid technical advancement in terrestrial and airborne lidar, it became possible to accurately describe and parameterize the three-dimensionally $A_{P A D}(x, y, z)$ variability of forest stands (Queck et al., 2012; Boudreault et al., 2015), leading to modeling attempts, in which the forest structure at the studied sites was more realistically reproduced (Schlegel et al., 2012; Boudreault et al., 2017). For single tree studies, the specific geometry of the studied tree is naturally of great importance and here we also use spatially varying $A_{P A D}$ in Eq. (1). In the few previous studies on single trees, the necessity for an adequate tree parameterization was also recognized in Endalew et al. (2009), whereas Bai et al. (2012) used idealized fractal trees for their wind tunnel work.

Detailed experimental data about air flow are paramount for the improvement of flow models. In heterogeneous forested terrain, full-scale field experiments have been made near forest edges (Raynor, 1971; Irvine et al., 1997; Dellwik et al., 2014), and larger scale experiments in heterogeneous forested terrain are currently carried out (Mann et al., 2017). However, much of our knowledge on wind flows over and in forests relies on wind tunnel studies using single-scale tree models like cylinders (Seginer et al., 1976; Poggi et al., 2004; Zhu et al., 2006; Segalini et al., 2013), strips (Raupach et al., 1986; Harman et al., 2016) or flexible stalks (Stacey et al., 1994). Also real trees have previously been put into wind tunnels (Vollsinger et al., 2005, e.g.,][), however, with the focus of studying the effect of wind on the tree, rather than the effect of the tree on the wind. These trees are typically young and flexible, due to the limited space in the wind tunnels, and to the authors' knowledge, no studies have been made on mature wind-adapted trees.

To address this issue, a full-scale field experiment with the aim of estimating the impact from a single, open-grown tree on the wind field was initiated. In addition to well-developed wind measurements technology, such as ultra-sonic anemometry, we use terrestrial lidar to determine the tree structure and develop a simple method to derive a tree model suitable for RANS and LES numerical experiments. This model is simpler than the methods used in Queck et al. (2012) and Béland et al. (2014). Together with strain gauges on the stem of the tree, that provide a measure of the total bending moment on the tree, we here demonstrate how $C_{d}$ can be directly estimated from the integral of Eq. (1). In this way, some of the uncertainty associated with variable values for $C_{d}$ (Rudnicki et al., 2004) can be avoided. When simulating flow over heterogeneous vegetation, the resolution of the studied feature may affect the final solution. To study this, we construct the $A_{P A D}$ tree at four different resolutions. The numerical experiment is performed with a RANS model, thereby testing a much-used and numerically inexpensive setup.

In summary, the aims of this study are to report the first observational data from a full-scale experiment on an open-grown tree, to characterize the tree such that it can be used in RANS and LES numerical experiments where the tree is represented as an $A_{P A D}$ model, to study how different tree resolutions affect the numerical results and to compare the results from the numerical experiment with observations.

\section{Methods}

\subsection{Site and observations}

In April 2017, a full-scale wind experiment was initiated around an open-grown European oak tree (Quercus Robur L.) at the Risø campus of the Technical University of Denmark. This tree was selected for a number of reasons: (i) a deciduous tree makes "two experiments in one", since the leaf-on and leaf-off conditions are dramatically different, (ii) the tree is robust and of a suitable height $(h \approx 6 \mathrm{~m})$, such that the wind conditions around it can be studied with short masts and (iii) the inflow conditions to the west, corresponding to the most common wind direction, are relatively uniform, with limited influence of land. The inflow conditions are shown in Fig. 1. In the directions of $280-290^{\circ}$, the fetch over water extends approximately $6 \mathrm{~km}$. To the north-

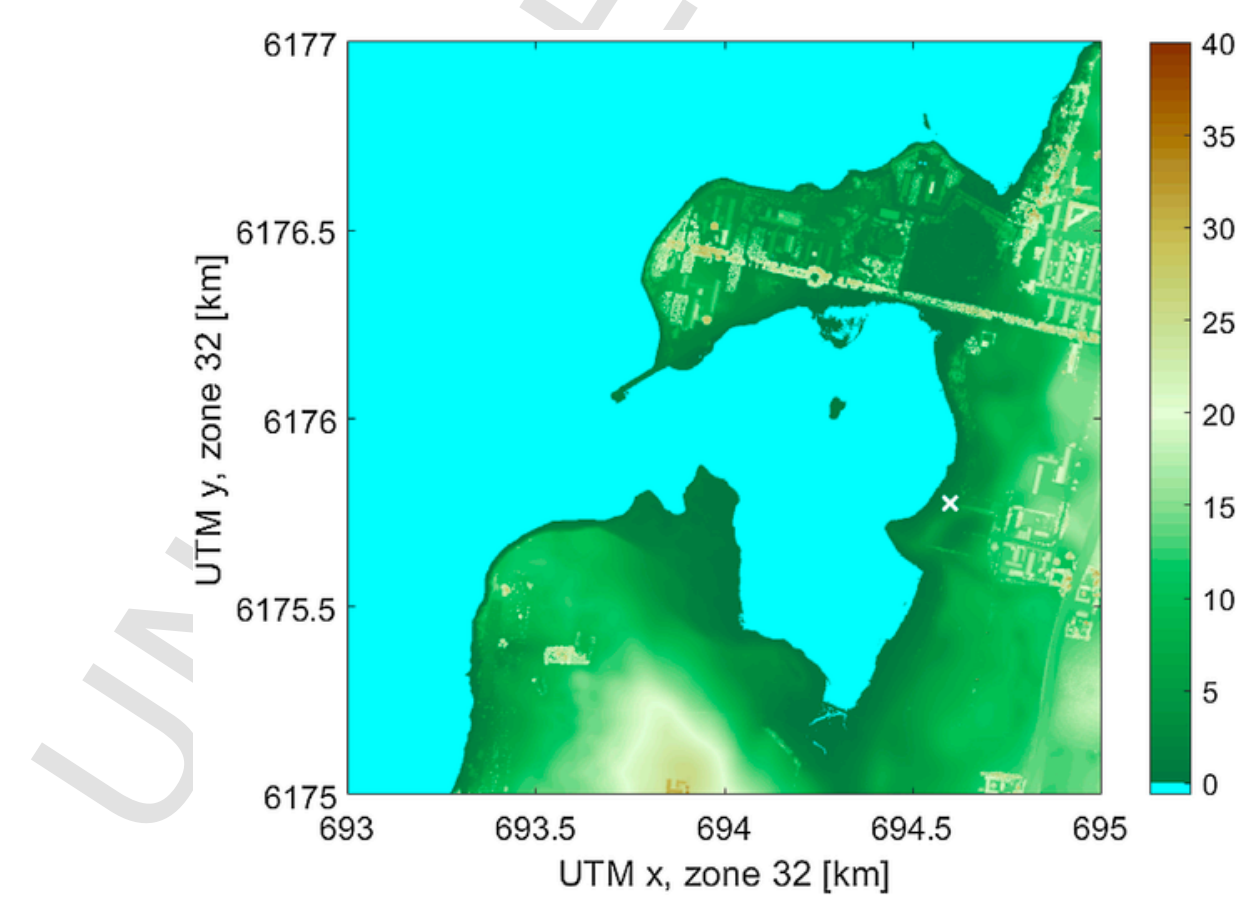

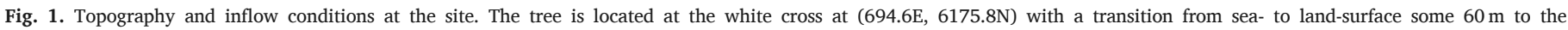
west-north-west. 
west and the southwest, the fetch over water is significantly shorter (around $500 \mathrm{~m}$ ) to either the Risø peninsula, which is covered by an alley and institute buildings to the north, or to low vegetation farmland to the south. The tree is located around $60 \mathrm{~m}$ from the shoreline (Fig. 2 ), which along the dashed line extends six kilometers over water. At such a short fetch, the tree is located inside an internal boundary layer (IBL) between the flows characterized by water and land surfaces. By assuming a land roughness length of $0.05-0.1 \mathrm{~m}$, the height of the lowermost part of the IBL, where the flow is in equilibrium with the land surface was estimated to be $1-1.5 \mathrm{~m}$ at the tree location (Dellwik and Jensen, 2000). The IBL height, above which the flow can be expected to be in equilibrium with the water surface, was estimated to approximately 8.5-12 m (Panofsky, 1973; Dellwik and Jensen, 2000). Hence, the experiment is located in flow which is in transition from sea to land conditions. The topography at the site is undulating and a small two meter tall ridge covered by bushes is located to the east of the tree (dashed line in Fig. 2A and grey dots in Fig. 2B).

Two twelve meter tall lattice masts with a square cross section of $0.3 \mathrm{~m}$ were placed upwind $(x=-15 \mathrm{~m})$ and downwind of the tree $(x=10 \mathrm{~m})$. The two masts were instrumented with an ultrasonic anemometer each (uSonic-3Basic, Metek Gmbh, Hamburg) at four meters height. The anemometers were placed on booms extending $1.6 \mathrm{~m}$ from the side of the mast in the $195^{\circ}$ direction. The locations of the two sonic anemometers are marked by squares in Fig. 2A and B. In addition to the sonic anemometers, two tree-adapted strain gauges (Blackburn, 1997; Moore et al., 2005) were installed on the western and the northern side of the tree trunk, respectively. This instrumentation (two sonic anemometers, two strain gauges) was consistently operational between April 6th and July 31st, 2017, which is the period used in this study. Since the leaves came out in May and the tree foliage was in transition, this month is excluded from the analysis. The strain gauges and the sonic anemometers were sampled at $20 \mathrm{~Hz}$ and the time series were stored on a computer.
The structure of the tree was determined by scanning it with a ground-based terrestrial lidar total station (Leica Nova MS60, Leica Geosystems AG, Switzerland) at $1000 \mathrm{~Hz}$ and $1 \mathrm{~cm}$ resolution. The tree with leaves was scanned in August 2016 (preceding the measurement campaign) from eight positions around the tree, and the tree without leaves was scanned early April 2017 from six positions. The scanning work was undertaken during very low wind speed conditions, in order to minimize the effects of branch and leaf movements. From the scans, the tree height was determined to be $6.4 \mathrm{~m}$ (here rounded to $h=6 \mathrm{~m}$ for scaling purposes), the crown width to be $8-9 \mathrm{~m}$, and the ground area covered by any part of the tree to be $46.4 \mathrm{~m}^{2}$.

\subsection{Processing of observational data}

\section{Strain gauge data}

The strain gauges were installed on caliper-shaped transducers using the design by Moore et al. (2005). The use of such transducers allows a rigid mounting on the tree and the monitoring of the bending moments on the tree by the wind. A challenge in using such an instrument configuration in a long-term measurement campaign, is its high temperature sensitivity. Due to the way that the transducer is mounted on the tree and to the thermal expansion of the material (aluminum), diurnal and seasonal temperature fluctuations result in a non-zero offset as first observed by Blackburn (1997). In addition, temporal drifts were observed in the strain gauge data which are associated to changes that occurred to the tree (e.g. the transition from no-leaves to leaves state). In a parallel study, Angelou et al. (2018) derives methods to overcome these issues and estimate the total bending moment on the tree and relate it to the wind speed observed at the $4 \mathrm{~m}$ sonic anemometer upwind of the tree crown. Below, we summarize the main findings of Angelou et al. (2018) for this study.

Three methods were presented for the post-processing of the temperature- and zero-drift affected strain gauge readings. All methods
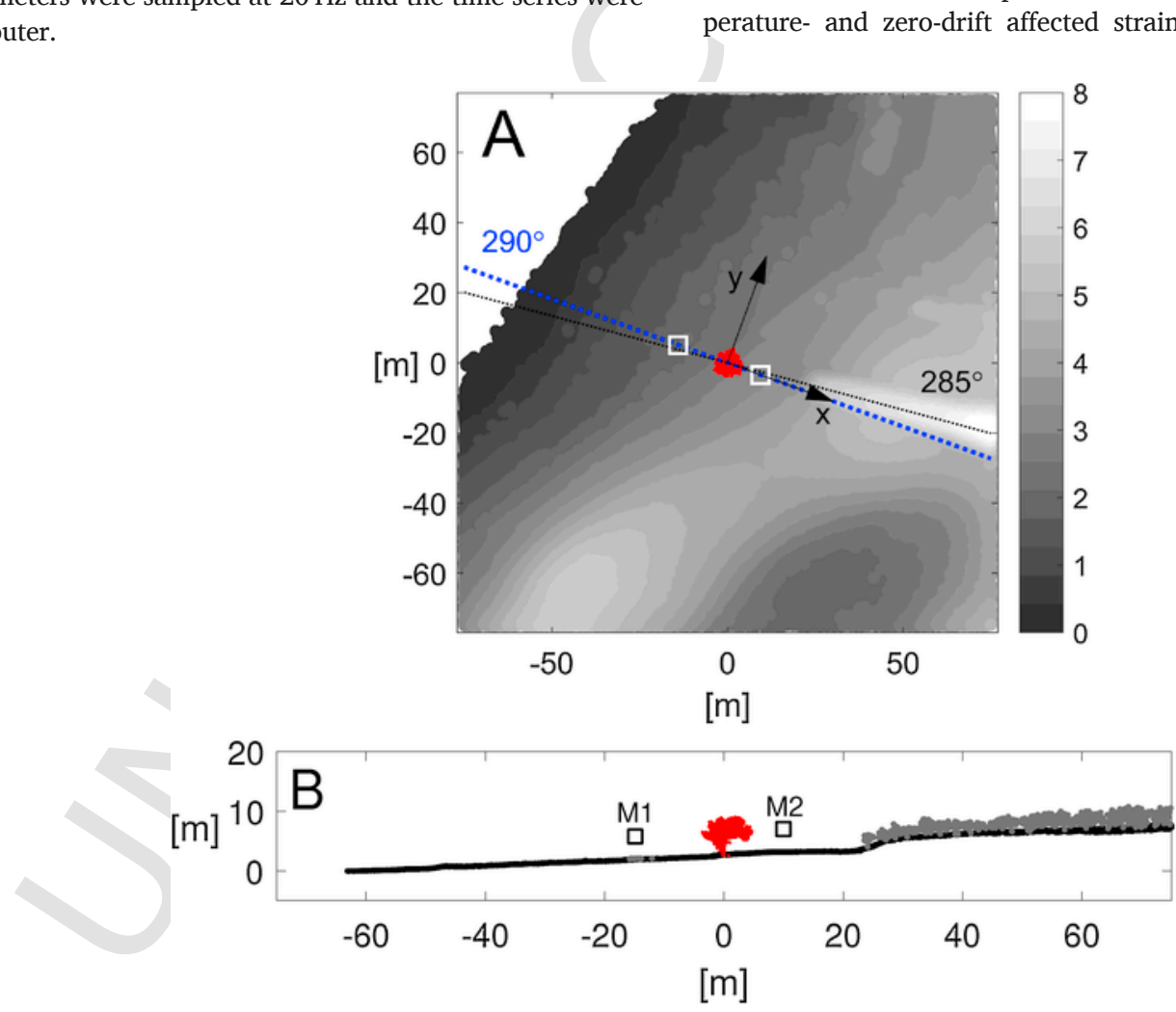

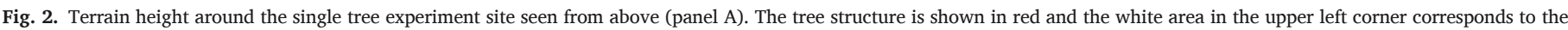

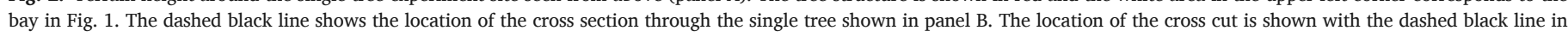

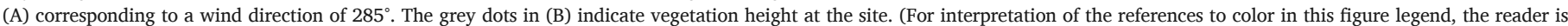
referred to the web version of this article.) 
were based on the observation that the temperature effects were slow relative to the response of the wind, and therefore temperature-related effects and zero-drift were considered to be constant on an hourly time scale. The coherence of the wind and strain signal was high for time scales down to one minute and therefore the wind-strain relationships were studied at this time scale. By a two-stage fitting procedure, the offset for each hour was removed and wind-strain relationships were constructed over a large wind speed interval. For the simplest method, temperature effects were not explicitly taken into account, whereas for the two other methods, temperature variability within each hour were further corrected using either a lab-based temperature-strain calibration curve or an in-situ calibration derived from low wind-speed periods.

In order to convert the strain readings to force, various static loads were applied to the tree during three different days, corresponding to both leaves-on and leaves-off cases. The applied loads were applied at $2 \mathrm{~m}$ height in the direction of $286^{\circ}$. The results of those pulling tests revealed a linear relationship between static loads and the strain measurements.

An assumption used in Angelou et al. (2018) is that the strain gauge observation were averaged over a long enough time interval to represent the mean bending moment over a static tree. The results for $6 \mathrm{~m} \mathrm{~s}^{-1}$ wind speed using the three slightly different methods for estimating the total bending moment on the tree are presented in the Table 1.

\section{Sonic anemometer data}

The raw data from the sonic anemometers were corrected for flow distortion and a spike detection filter was run on velocities rotated to a coordinate system defined by the three paths of the anemometer as in Dellwik et al. (2014). Subsequently the data were rotated such that $V=W=0$ for 10 min block averages, where $V$ and $W$ are the wind component in the mean cross-wind and vertical directions, respectively. The $10 \mathrm{~min}$ averages were filtered for neutral stability by requiring that $-0.1 \leq z / L \leq 0.07$, where $L$ is the Obukhov length, which is also calculated from the sonic anemometer data.

Based on observations of the tree under high wind conditions, we judge that the wind causes the tree to streamline only to a limited extent. Nevertheless, to avoid such effect, we chose to limit the work to a single and relatively low wind speed $U$ by requiring that $5 \leq U \leq 7 \mathrm{~m} \mathrm{~s}^{-1}$, where we assume that the structure of the tree is still near-identical to the structure revealed, when scanning the tree under very low wind speed conditions. By filtering for wind direction, wind speed interval and neutral atmospheric stability, the summer and winter datasets were reduced to $13 \%$ (1130 ten minute runs) and 17\% (468 ten minute runs) of the original datasets, respectively. When comparing with model simulations, where the results are sensitive to the turbulence level in the inflow, a further refinement was applied by marking the data that were close to the simulated inflow turbulence intensity $I_{M 1} \approx \sqrt{2 k / 3} / U_{M 1}=11 \%$, where $k=\frac{1}{2}\left(\sigma_{u}^{2}+\sigma_{v}^{2}+\sigma_{w}^{2}\right)$. For the summer datasets 433 runs met the criteria $10 \% \leq I_{M 1} \leq 12 \%$ and for the winter

Table 1

Mean bending moments (forces) for a center-crown inflow wind speed of $6 \mathrm{~m} \mathrm{~s}^{-1}$ using the three methods for drift and off-set removal in Angelou et al. (2018). The forces were estimated using a centroid of the drag at $3.8 \mathrm{~m}$ height, which, in turn, was estimated from the centroid point of the summer and winter scans.

\begin{tabular}{|c|c|c|c|c|}
\hline Tree state & $\begin{array}{l}\text { Off-set } \\
\text { correction } \\
\text { only }\end{array}$ & $\begin{array}{l}\text { Lab temperature } \\
\text { correction }\end{array}$ & $\begin{array}{l}\text { Air temperature } \\
\text { correction }\end{array}$ & Mean value \\
\hline Summer & $\begin{array}{l}3055 \mathrm{Nm} \\
(804 \mathrm{~N})\end{array}$ & $\begin{array}{l}2911 \mathrm{Nm} \\
(766 \mathrm{~N})\end{array}$ & $\begin{array}{l}2846 \mathrm{Nm} \\
(749 \mathrm{~N})\end{array}$ & $\begin{array}{l}2937 \mathrm{Nm} \\
(773 \mathrm{~N})\end{array}$ \\
\hline Winter & $\begin{array}{l}1129 \mathrm{Nm} \\
(297 \mathrm{~N})\end{array}$ & $\begin{array}{l}1167 \mathrm{Nm} \\
(307 \mathrm{~N})\end{array}$ & $\begin{array}{l}1170 \mathrm{Nm} \\
(308 \mathrm{~N})\end{array}$ & $\begin{array}{l}1115 \mathrm{Nm} \\
(293 \mathrm{~N})\end{array}$ \\
\hline
\end{tabular}

dataset, 122 ten minute samples were marked as being very close to the modeled inflow conditions.

\section{Development of the $A_{P A D}$ tree model}

The raw data from the terrestrial lidar scan was transformed to a plant area density $\left(A_{P A D}\right.$ in Eq. (1)) tree model suitable for the CFD simulations as follows: the raw data from the scanner form a so-called point cloud, which consists of the $(x, y, z)$ coordinates of the terrestrial lidar reflections on different surface elements of the tree (steam, branch, twig, leaf). The point clouds from all scanning positions were merged into one dataset for the winter and the summer trees, respectively. Subsequently, the following steps were performed:

1 Removal of outliers. Outlier reflection points could be caused by real objects, for example insects, or be caused by an instrumental problem. For the winter tree, characterized by bare branches and twigs, the data sometimes showed thin streaks of reflection points in between two thin branches. By visual inspection, it was easy to judge that these points did not represent a tree surface, but rather were caused by an instrumental algorithm that placed points in between two surfaces. For the summer tree, such points were less evident. Because the summer tree is dense, it was harder to resolve all surfaces from multiple angles, making the scanning density lower. For this reason, the outlier filtering was performed with different thresholds for the winter and the summer tree; point densities $\leq 1$ points/ $4 \mathrm{~cm})^{3}$ was filtered out for the summer trees, whereas the corresponding threshold for the winter tree was $\leq 1$ points $/(2 \mathrm{~cm})^{3} \cdot 8.1 \%$ and $4.5 \%$ from the cloud points were flagged as outliers in the case of the summer and the winter tree, respectively.

2 Removal of duplicates. The volume around the tree was subdivided into voxels of $2 \mathrm{~cm} \times 2 \mathrm{~cm} \times 2 \mathrm{~cm}$. Positions of all the reflection points within each voxel were averaged and the mean position of these reflections was saved. This step ensures that areas that were covered from multiple scanning positions did not get a disproportionately high weight in the final model.

3 Assignment of area. An area of $a=2 \mathrm{~cm} \times 2 \mathrm{~cm}$ was assigned to each point.

4 Calculation of plant area density. $A_{P A D}$ values were calculated to retain different levels of detail in the tree models

$A_{\mathrm{PAD}}=N \times a / \Delta^{3}$,

where $\Delta=0.125,0.25,0.5,1 \mathrm{~m}$, which correspond to $h / 48, h / 24$, $h / 12$ and $h / 6$, respectively.

The resulting $A_{P A D}$ models are highly sensitive to the choices of voxels volumes and assigned areas in Steps 2 and 3. An overlap in scanning points can only be expected if we choose voxels sizes that are slightly higher than the scanning resolution $\left(1\right.$ point per $\left.\mathrm{cm}^{-2}\right)$ and this was the motivation of choosing voxel volumes of $2 \mathrm{~cm} \times 2 \mathrm{~cm} \times 2 \mathrm{~cm}$ and $a=2 \mathrm{~cm} \times 2 \mathrm{~cm}$, respectively. As will be shown below, the potential bias due to these heuristic choices is counterbalanced, when calibrating the effect of the model tree.

\subsection{Numerical setup and simulations}

\section{Solver and model constants}

The RANS simulations were performed with EllipSys3D, a finite volume code developed at DTU Wind Energy (Sørensen, 1994; Michelsen, 1992). The pressure is solved with the SIMPLE algorithm (Patankar and Spalding, 1972) and the QUICK scheme (Leonard, 1979) is employed to discretize the convective terms. Since the pressure and velocity vector are stored at the cell centers, a modified Rhie-Chow algorithm (Rhie and Chow, 1983; Réthoré and Sørensen, 2012) is used to avoid pressure-velocity decoupling. 
In this work, the RANS simulations of the single tree were kept as simple as possible. We use flat terrain with a uniform roughness height, neutral atmospheric conditions and we neglect the Coriolis acceleration. The tree is modeled as a distributed sink in the momentum equations following Eq. (1). Viscous effects were considered negligible, since the strain gauge observations indicated a force-wind speed relationship close to $U^{2}$ for the wind speed interval of $5 \leq U \leq 7 \mathrm{~m} \mathrm{~s}^{-1}$ (Angelou et al., 2018).

The Reynolds-stress tensor is modeled with the standard $k$ - $\varepsilon$ model (Launder and Spalding, 1972), where $\varepsilon$ is the dissipation rate. The model constants were taken from Richards and Hoxey (1993) for atmospheric flows $\left(C_{\mu}, \sigma_{k}, \sigma_{\varepsilon}, C_{\varepsilon, 1}, C_{\varepsilon, 2}, \kappa\right)=(0.03,1.0,1.3,1.21,1.92,0.4)$, and an additional source term was added in transport equation for $\varepsilon$ (Sogachev and Panferov, 2006):

$S_{\varepsilon}=C_{d} \rho A_{\mathrm{PAD}}|U| \beta \sqrt{C_{\mu}}\left(C_{\varepsilon, 2}-C_{\varepsilon, 1}\right) k \frac{\varepsilon}{k}$,

where $\beta=12$ is a parameter calibrated to fit observed wind profiles over and inside the Moga forested areas (Ayotte et al., 1999; Sogachev et al., 2012b). $S_{\varepsilon}$ reduces the turbulent kinetic energy in the wake of tree, which delays the recovery of the wake.

\section{Grid and boundary conditions}

The numerical grid is depicted in Fig. 3, where every eighth grid line is shown. The domain extends $100 \mathrm{~h} \times 100 \mathrm{~h}$ and $20 \mathrm{~h}$ in the horizontal $(x, y)$ and vertical $(z)$ directions respectively. The bottom of the tree trunk is placed at the origin of the flow domain. Around the tree, a uniform spaced high-resolution region of $4 h \times 12 h \times 2 h$ is defined (marked as blue mesh lines in Fig. 3). In this region we use different grid resolution $\delta$. In a first step of the analysis, the grid resolution $\delta$ was always the same as the tree model resolution $\Delta$. The investigated grid sizes are: $\delta=\Delta=h / 6, h / 12, h / 24, h / 48$, which correspond to a total $0.26,1.2,5.4$ and 21 million number of cells, respectively. In a second step of the analysis, the value of $\Delta$ was kept constant, while $\delta$ was refined. This step shows how fine a grid we need to achieve a grid-independent solution. Outside the uniformly spaced region, the grid is stretched towards the boundaries with a refinement ratio of 1.2 .

At the boundary $x=-50 h$ and at the top of the domain $(z=20 h)$, an inlet boundary condition is used, where a neutral logarithmic sur- face layer profile is applied:

$$
\begin{aligned}
U & =\frac{u_{*}}{\kappa} \ln \left(\frac{z+z_{0}}{z_{0}}\right), \quad k \\
& =\frac{u_{*}^{2}}{\sqrt{C_{\mu}}}, \quad \varepsilon \\
& =\frac{u_{*}^{3}}{\kappa\left(z+z_{0}\right)},
\end{aligned}
$$

where $U$ is the streamwise velocity component, $u_{*}$ is the friction velocity and $z_{0}$ is the roughness length. The latter two parameters were extracted by requiring a velocity of $U_{\text {ref }}=6 \mathrm{~m} \mathrm{~s}^{-1}$ and a turbulence intensity $I_{\text {ref }}=\sqrt{2 / 3 k} / U_{\text {ref }}=11 \%$, taken at a reference height $z_{\text {ref }}=4 \mathrm{~m}$ :

$u_{*}=U_{\mathrm{ref}} I_{\mathrm{ref}} \frac{\sqrt[4]{C_{\mu}}}{\sqrt{\frac{2}{3}}}, \quad z_{0}=\frac{z_{\mathrm{ref}}}{\exp \left(\frac{\kappa \sqrt{\frac{2}{3}}}{I_{\mathrm{ref}} \sqrt[4]{C_{\mu}}}\right)-1}$

This gives $u_{*}=0.34 \mathrm{~m} \mathrm{~s}^{-1}$ and $z_{0}=3.2 \times 10^{-3} \mathrm{~m}$. This roughness length lies between a typical grass roughness height and a water surface roughness, which can be explained by the presence of the fjord. The bottom boundary $(z=0)$, is a rough wall at which the velocity and the gradient of $k$ normal to the wall are zero, and the turbulent dissipation $(\varepsilon)$ is prescribed (Sørensen et al., 2007). The side boundaries $(y= \pm 50 h)$ are symmetry boundaries. The boundary at $x=50 h$ is an outlet, where a zero gradient assumption is used in the direction normal to the outlet plane. The inflow vector at the inlet is always aligned with the grid lines $(U(z), 0,0)$ to minimize numerical diffusion. The tree at the origin is rotated to simulate different wind directions.

\subsection{Tree model calibration}

In order to validate the RANS simulations with the measured wake deficit, the simulated total bending moment was matched to the mean of the values shown in Table 1 for the summer and winter tree, respectively. This calibration was carried out by tuning the drag coefficient $C_{d}$ from Eq. (1). The modelled total bending moment was calculated from

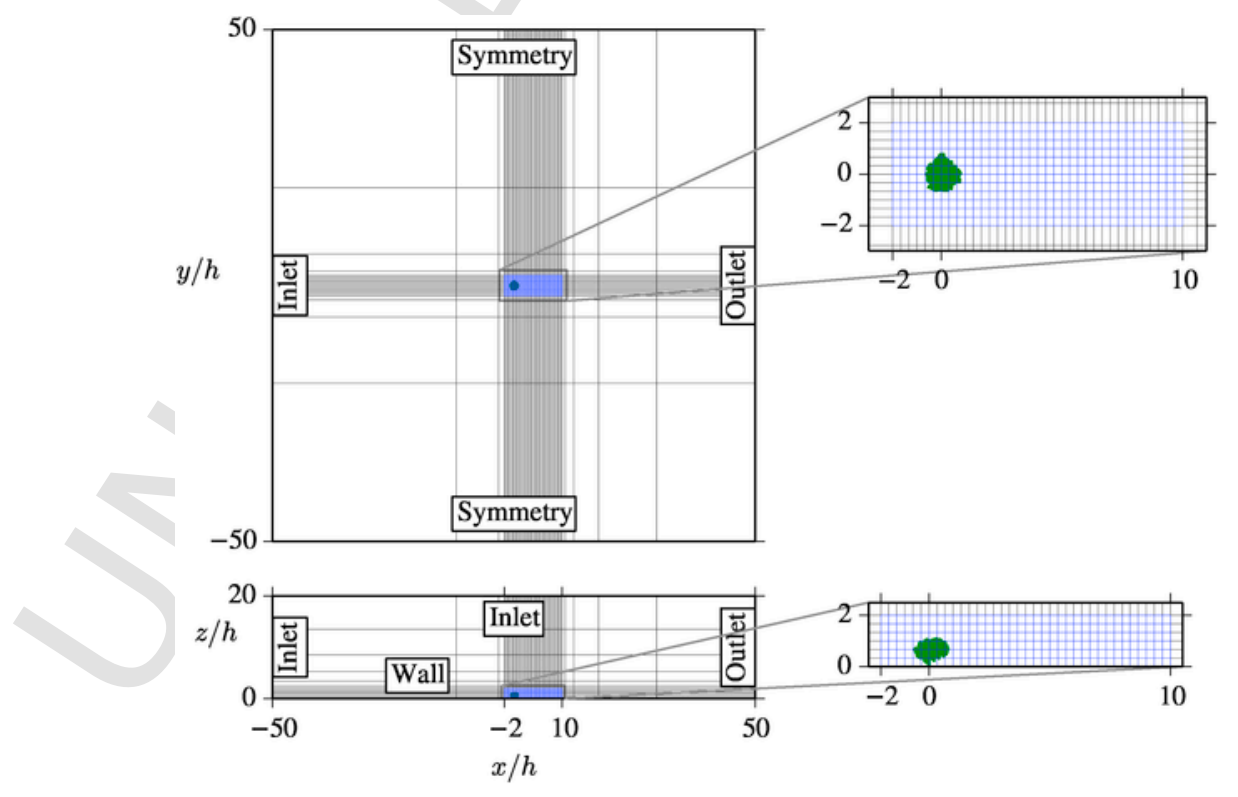

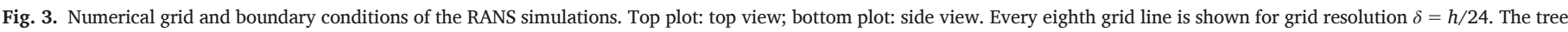

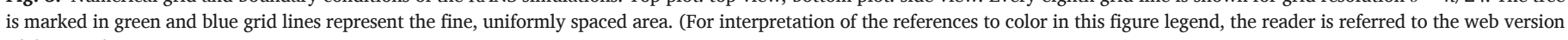
of this article.) 
$M_{y}=\mathbf{e}_{y} \cdot \iiint \mathbf{F} \times \mathbf{r} \mathrm{dx} \mathrm{dy} \mathrm{dz}$

where $\mathbf{r}$ is the vector from origin (the centre of the stem at $z=0$ ) to the voxels at $\mathbf{r}=(x, y, z)$ of the tree model and $\mathbf{e}_{y}=(0,1,0)$ is a unit vector in the $y$-direction. To find the correct $C_{d}$, a gradient-based optimization routine was used, where the cost function is the error between the measured and simulated $M_{y}$.

\section{Results}

\subsection{Tree models}

The four different resolutions $(\Delta=h / 6, h / 12, h / 24, h / 48)$ of the $A_{P A D}$ tree models are shown in Fig. 4 , in which the tree is viewed from the M2 position towards the $-x$ direction as defined in Fig. 2. The upper row shows the results from the summer scan, when the tree had leaves, and the lower row shows the corresponding results for the win- ter tree. The majority of the dense areas of the tree are located in the crown in the range of $-0.5 \leq y / h \leq 0$, revealing an asymmetry in the crown. The $A_{P A D}$ values of the stem are lower than in the crown, which in the applied CFD model will result in the stem being relatively more porous to the wind than the crown. The $A_{P A D}$ was integrated over both the horizontal dimensions and subsequently divided by the vertically projected ground area (the area in shade at noon, had the tree been moved to the equator) to yield the mean plant area density profile $\bar{A}_{\mathrm{PAD}}(z)$ in $\mathrm{m}^{2} / \mathrm{m}^{3}$ (Fig. 5). The maximum density occurs at $z / h=0.6$ for the winter tree, whereas it is moved slightly downwards for the summer tree. The maximum density changes approximately by a factor of three from the winter to the summer state.

\subsection{Determination of local $C_{d}$}

The value of the drag coefficient was determined based on simulations along a single wind direction in the $x$ direction $\left(290^{\circ}\right)$. The calibration is site-specific in that it is dependent on the local inflow parameters $U_{\text {ref }}=6 \mathrm{~m} \mathrm{~s}^{-1}$ and $I_{\text {ref }}=11 \%$.
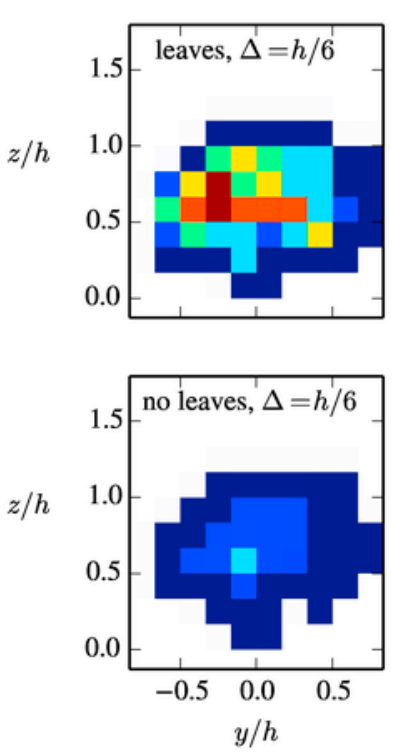
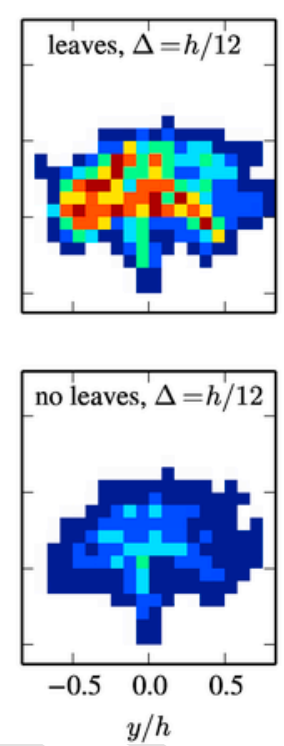
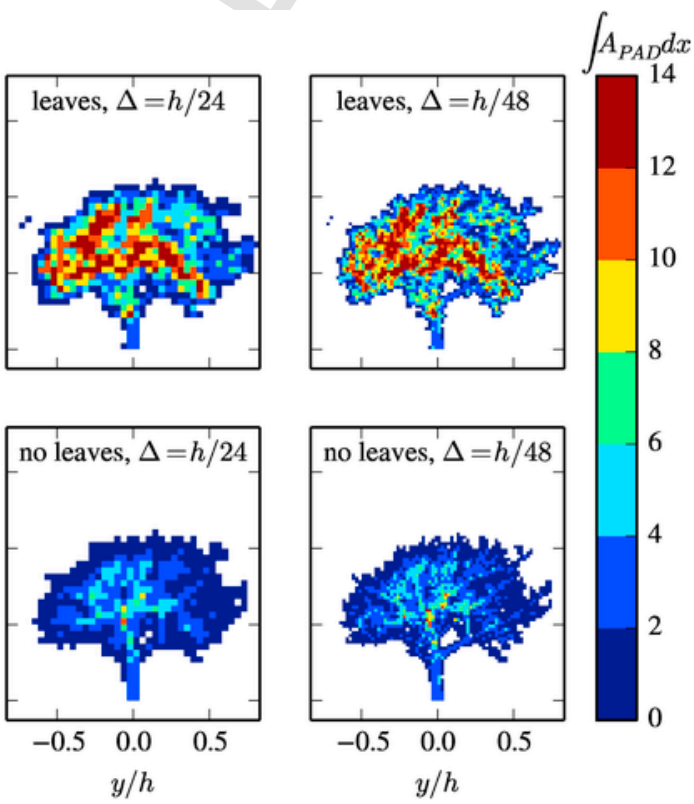

Fig. 4. $A_{P A D}$ integrated over $x$ for the tree with and without leaves for four different grid sizes.

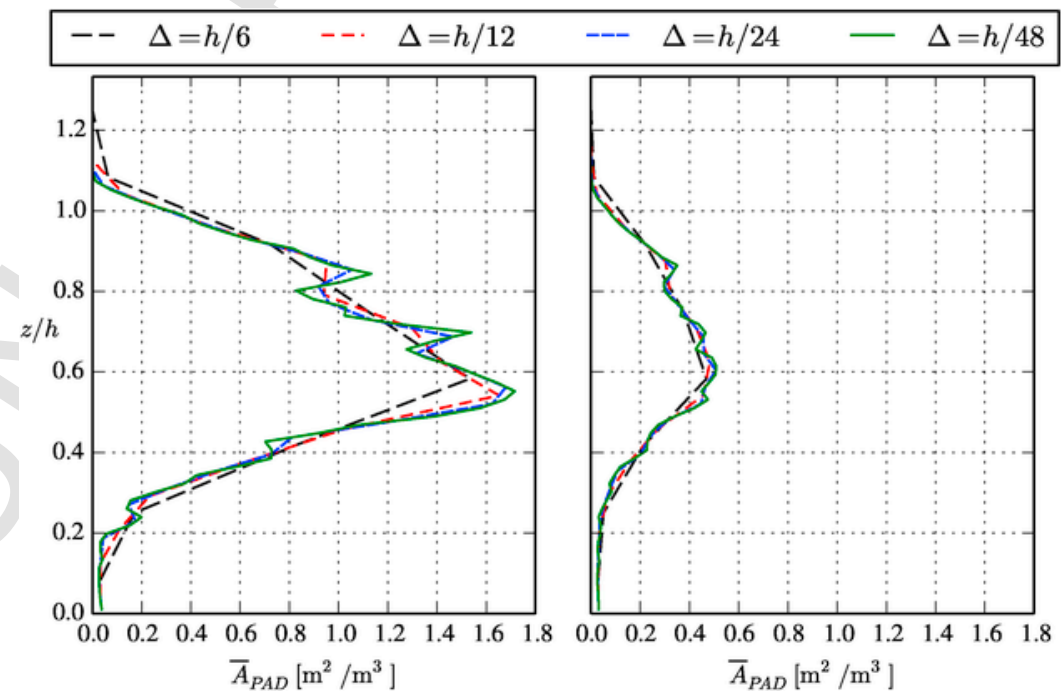

Fig. 5. Estimation of plant area for the tree with and without leaves for four different grid sizes. 
The bending moment on the simulated tree at different tree resolution $\Delta$ changes as function of the local drag coefficient, both for different model resolutions of the summer tree with leaves (green curves) and winter tree without leaves (brown curves) (Fig. 6). The total drag force first increases rapidly with $C_{d}$ and then levels off and asymptotically reaches a maximum value. It is clear that the maximum achievable bending moment depends on tree model resolution; the coarser the tree model resolution, the higher is the maximum bending moment that can be achieved. For the summer tree with leaves, we can only achieve the observed bending moment by use of the coarsest tree model (black lines in Fig. 6) using $C_{d}=0.389$. For the bare tree without leaves, the observed bending moment of $1115 \mathrm{Nm}$ can be achieved with all tree models using $C_{d}=0.16$. It is important to note that the calibration is highly dependent on the tree model, such that any error in the tree model directly changes the $C_{d}$. For example, if the chosen value for $a$ (see Section 2.2) would be higher, then the $C_{d}$ needs to be lower in order to obtain the same total bending moment.

For the results in Fig. 6, the grid resolution $\delta$ equals the tree model resolution $\Delta$. For a coarse grid, unavoidable numerical errors due to numerical diffusion are greater than those based on a high resolution grid. We then refined $\delta$ on a fix tree model resolution of $\Delta=h / 6$. When refining the numerical grid for the summer tree model to $\delta=h / 24$, this error should be reduced. Fig. 7 shows how the bending moments are increased when refining the grid resolution. Since the bending moment is relatively insensitive to $C_{d}$ for the high summer values, this refinement leads to large difference in the resulting value of $C_{d}=0.264$ (Fig. 7). For the winter tree without leaves, the increased grid resolution leads to a smaller change of $C_{d}$ to 0.147 .

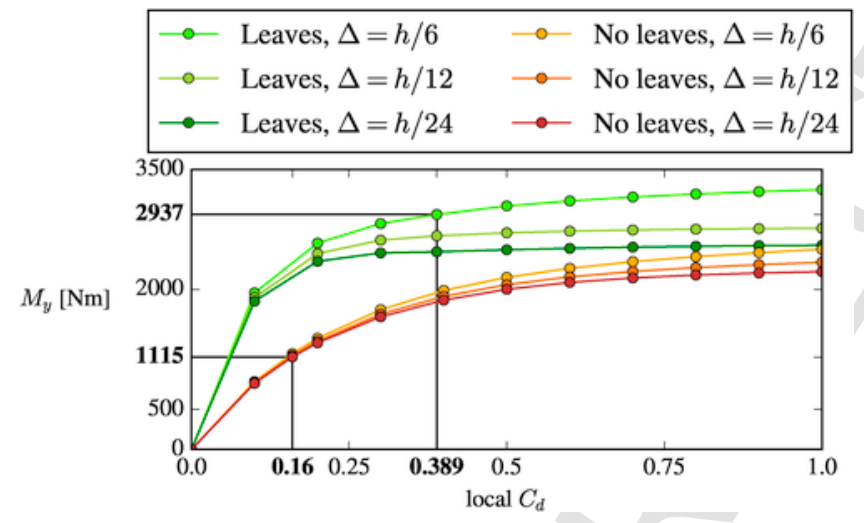

Fig. 6. Bending moment versus $C_{d}$ for the tree with and without leaves for three different tree model and grid resolutions, $\Delta=\delta$. The observed bending moment and the resulting $C_{d}$ values are indicated in bold.

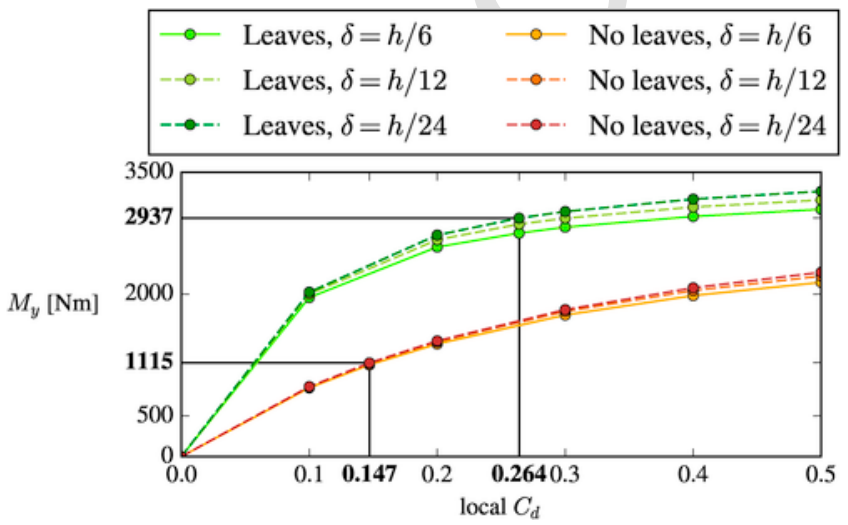

Fig. 7. Bending moment versus $C_{d}$ for a fix tree model resolution $\Delta=h / 6$ with and without leaves for three different flow domain grid resolutions $\delta$. The observed bending moment and the resulting $C_{d}$ values are indicated in bold.
Fig. 8 shows the influence of the grid resolution $\delta$ on the simulated mean wind speed in the wake (left column) and the turbulence intensity relative to the upwind velocity $I=\sqrt{2 / 3 k} / U_{\text {ref }}$ (right column). The results are extracted along a line in the $y$-direction at $(x, z)=(10,4) \mathrm{m}$. For the wind speed, the simulation results from the different grid resolutions are so close that they could not be distinguished, but the turbulence intensity shows a greater dependence on grid size. When refining the resolution successively by a factor of two, the model results are increasingly close to each other and the solution converges. The distances between the curves are an indication of how the error diminishes due to numerical diffusion. From these results, using Richardson extrapolation together with a Mixed-Order Analysis (Roy, 2003; Réthoré et al., 2014), we can estimate the solution for an infinitely fine grid, and hence also the remaining error at finite grid resolutions. We find that for $\delta=h / 24$, the numerical error is below $1 \%$ for the peak turbulence intensity of the summer tree (Fig. 8, bottom right). For the comparison with observational wind data, we consider this error acceptable and proceed with the tree models resolution $\Delta=h / 6$ and grid resolution $\delta=h / 24$.

\subsection{Wind observations and model validation}

The comparison between wind observations and simulations are shown as a function of wind direction in Fig. 9. To capture the wind direction effects on the tree in the simulations, the tree was rotated in the simulation grid. All the quality-controlled, near-neutral data with a $5 \leq U_{M 1} \leq 7 \mathrm{~m} \mathrm{~s}^{-1}$ are shown as grey circles, whereas the data with $10 \% \leq I_{M 1} \leq 12 \%$ are shown with red circles in Fig. 9. The velocity deficit from the measurements that is filtered for turbulence intensity does not change significantly compared to the unfiltered measurements, while the filtering mostly affects the turbulence intensity at the wake edges, where the fetch over land is longer which results in a higher observed turbulence intensity.

The observational results in Fig. 9 shows that the velocity deficit (left column) in the wake of the tree is asymmetric, which can be explained by the asymmetry of the tree (Fig. 4). The observed turbulence intensity (right column) also shows asymmetry. For the summer tree with leaves, the observations indicate a decrease in the turbulence in the inner wake and an increase of the turbulence near the edge of the wake, whereas for the winter tree without leaves, the turbulence observations in the wake indicate a decrease only. The maximum magnitude of the wake deficit changed between $90 \%$ (summer tree with leaves) and $\approx 35 \%$ (bare winter tree).

The simulations (green lines in Fig. 9) capture both the asymmetry of the wake and the wake turbulence behaviour well. For the summer tree, the wake wind speed is slightly underestimated, whereas it is slightly overestimated for the winter tree. The mean absolute wind speed errors were $5 \%$ and $3 \%$ for the summer and winter trees, respectively. The errors are typically positive (summer tree with leaves) or systematically negative (bare winter tree). When integrating the wind speed deficit over the wind direction interval of the wake, the error is $-20 \%$ for the winter tree, but only $7 \%$ for the summer tree. The largest discrepancy between simulated and observed wake flow occurs for the turbulence intensity of the "No leaves" case (Fig. 9, upper right).

To match the simulated wake with the observed wake, the observed M2 wind directions was rotated southward by $7^{\circ}$; the modeled wake showed no change in wind direction relative to the upwind direction (not shown). The turning of the wake could be explained by terrain effects, and more specifically the ridge downwind of the tree in the $285^{\circ}$ direction (Fig. 2 B), that are not modeled in the RANS simulations. A part of the off-set could also be due to the downwind sonic anemometer being oriented slightly differently than the upwind sonic, which would lead to an error in the observed wind direction. 


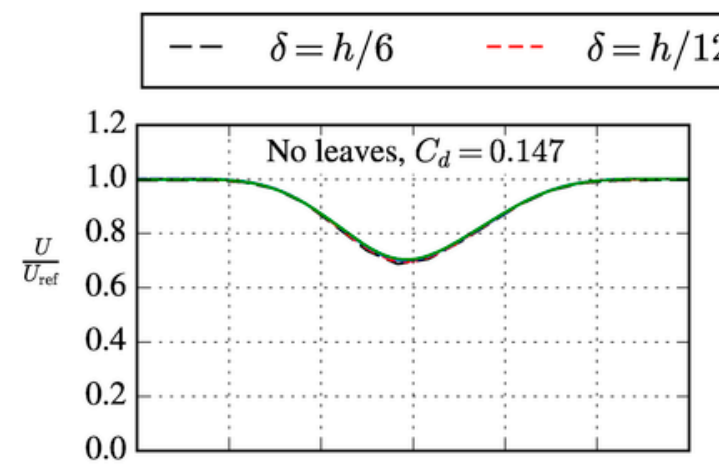

$$
---\delta=h / 24 \quad-\quad \delta=h / 48
$$
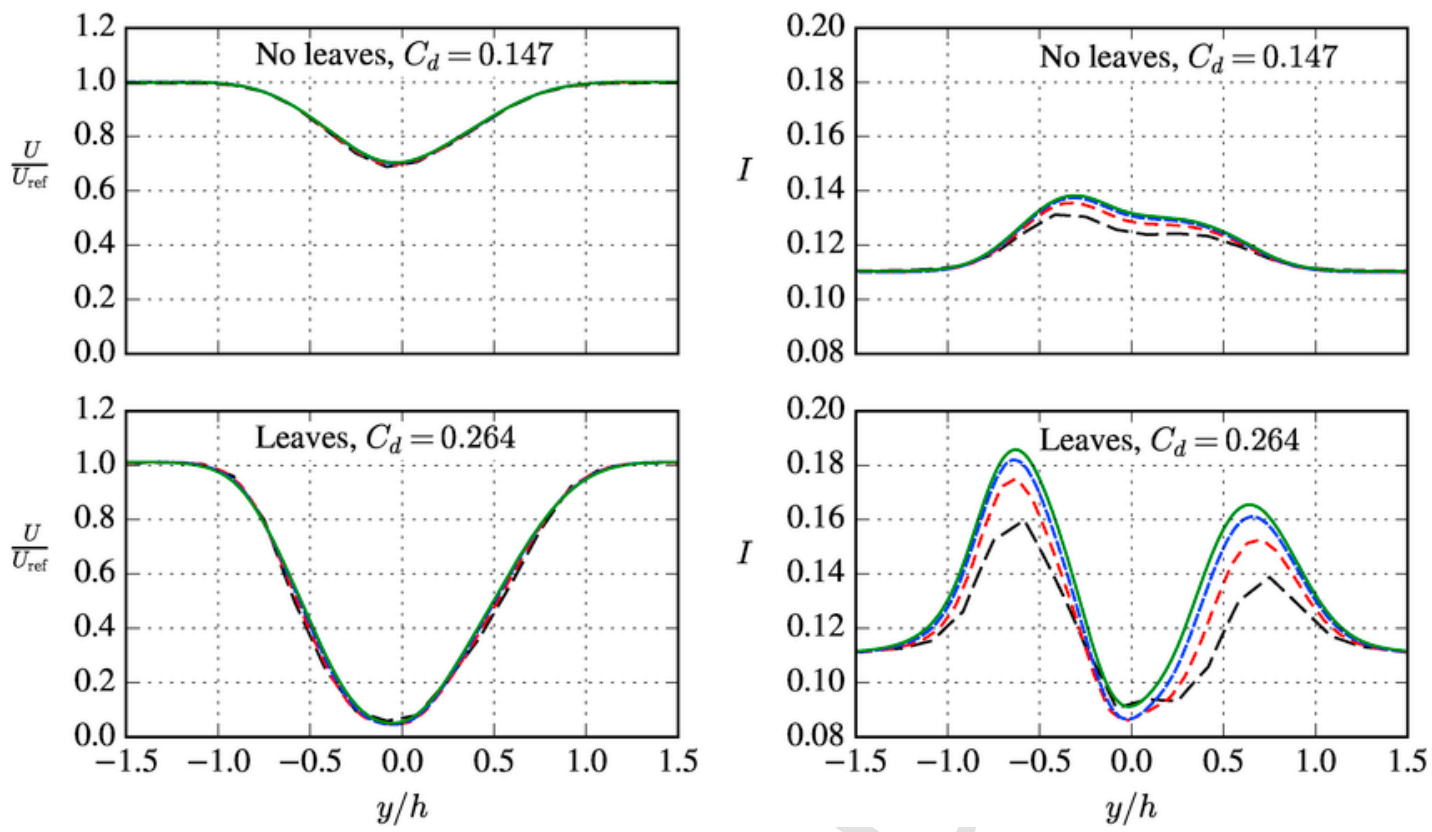

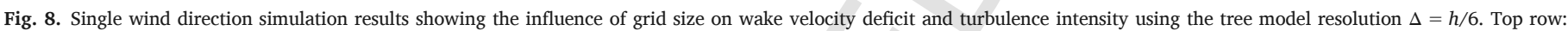
winter tree without leaves, $C_{d}=0.147$; bottom row: summer tree with leaves $C_{d}=0.264$. The results were extracted along a line in the $y$-direction at $(x, z)=(10,4) \mathrm{m}$.
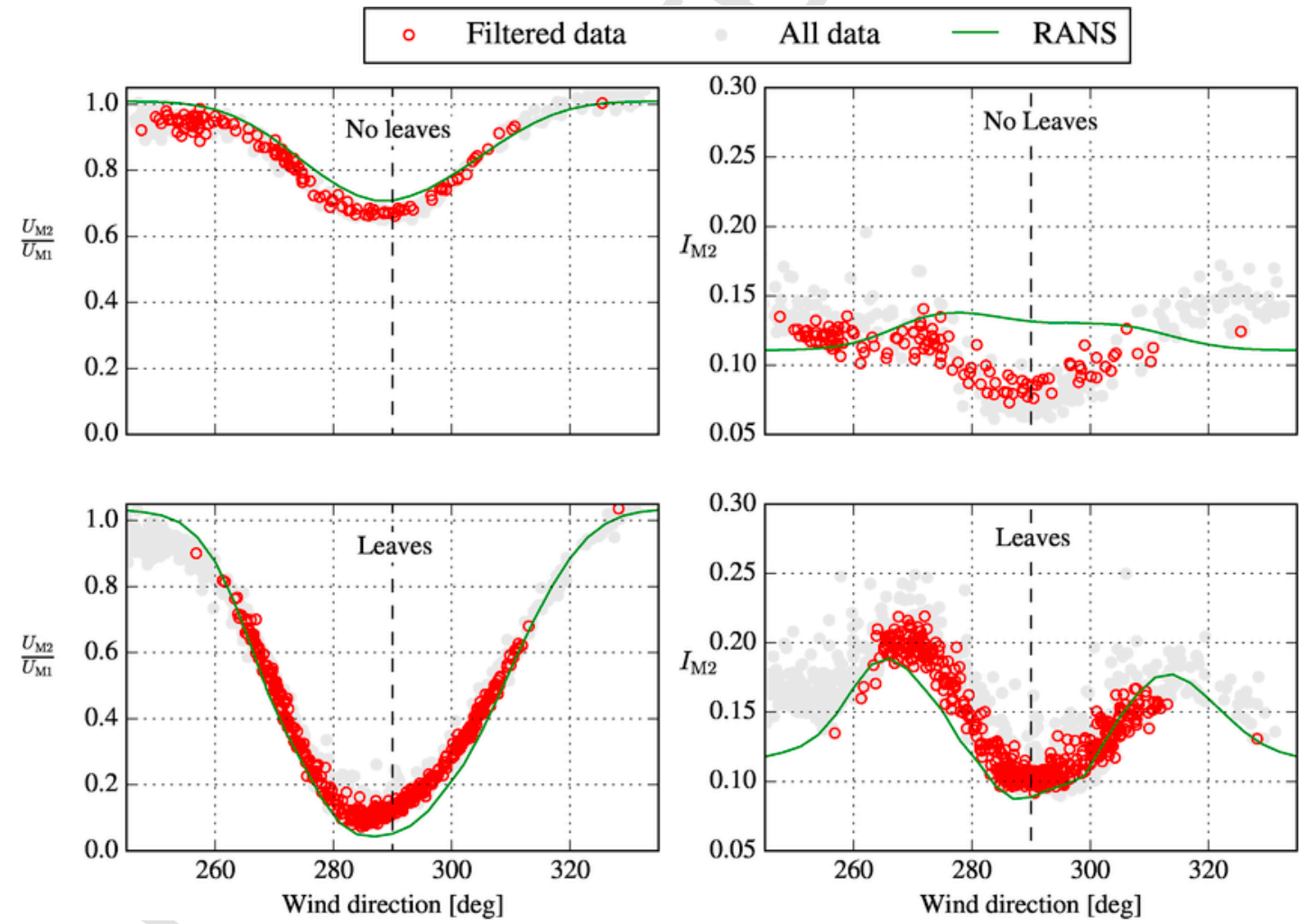

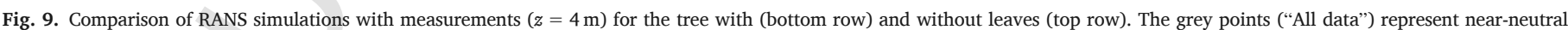

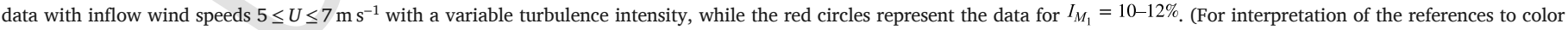
in this figure legend, the reader is referred to the web version of this article.) 


\subsection{Wake planes}

A simulated mean wind speed plane through the summer tree is shown in Fig. 10 for a wind direction of $290^{\circ}$. Each subplot represents a different cross plane taken at $y / h=-0.25,0$ and 0.25 . The contours of the streamwise velocity normalized by the inflow profile are shown together with contours of the absolute value of the drag force distribution of the tree (grey scale on the tree). The largest drag force occurs on the higher branches on the upwind (left) side of the tree in Fig. 10, where the local velocity is high. The middle plot of Fig. $10(y / h=0)$ also shows the location of the two sonic anemometers. It appears that the down wind sonic anemometer is placed at the location of the maximum velocity deficit in the wake. At all three planes, an increase of the mean wind speed above the crown and behind the stem can be distinguished. At around $x=5 h$, the wind speed in the wake has recovered to $50 \%$ relative to the inflow wind speed. For all the wake planes, the wake is tilted downwards and extends far behind the tree.

\section{Discussion}

\subsection{Uncertainties}

All the key components in the presented analyses are affected by uncertainty. The tree model was based on a very simple algorithm compared to Queck et al. (2012) and Béland et al. (2014). An assumption in our model is that all areas of the tree are covered by the scans at a high resolution, and it is hard to judge whether this assumption is justified. However, the resulting $\bar{A}_{\text {PAD }}$ profile in Fig. 4 shows similarity in magnitude of the profiles as estimated by e.g., Lalic and Mihailovic (2004), which is encouraging. Also, systematic errors made in the $A_{P A D}$ tree model will be balanced in the calibration step where the simulated bending moment is matched to the value of the observations in Fig. 6 . The wind measurements are less uncertain, because we present ratios of wind measurements for which at least part of the systematic instrumental error can be assumed to disappear, since the error should be similar for the two sonic anemometers. A further potential source of error is the choice of an equilibrium inflow profile, used for the RANS simulation, where the tree in reality is located in an internal boundary layer.

\subsection{Drag coefficient}

Several authors have noted the difficulty of correctly prescribing $C_{d}$ in forest canopy modeling (e.g.(Brunet et al., 1994; Ayotte et al., 1999; Pinard and Wilson, 2001). From our calibration of $C_{d}$ in Fig. 6, two regimes in the force $-C_{d}$ plot can be defined; one near-linear regime, and one saturated regime, in which the force is independent of the cho-

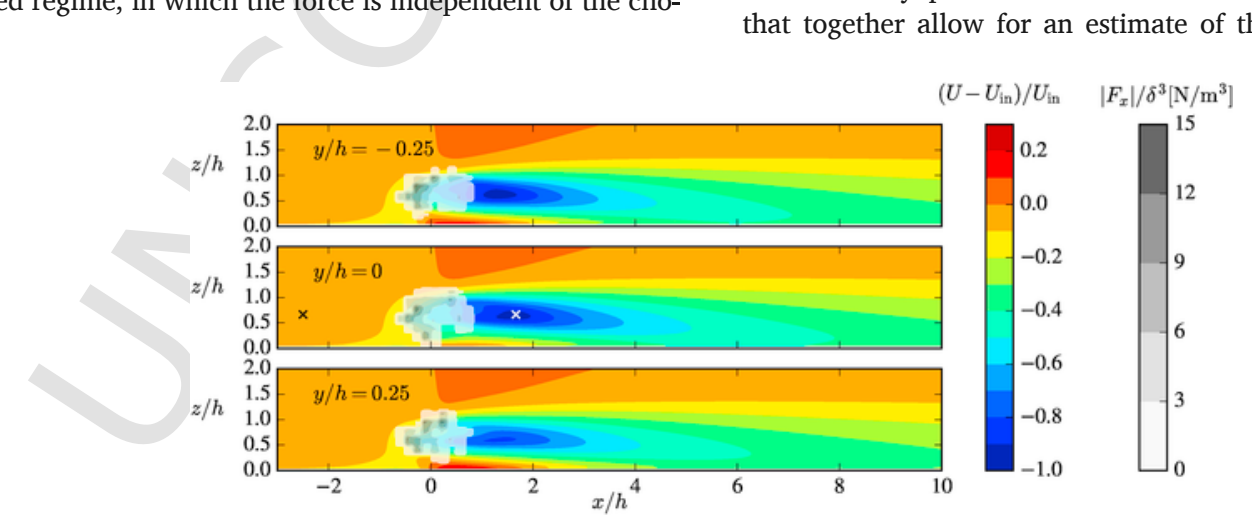

sen $C_{d}$. It is therefore only meaningful to compare $C_{d}$ values from different studies if they lie outside the saturated regime. For the calibrated tree model with resolution $\Delta=h / 6$, the summer and winter tree calibration curves differ, because the summer tree $A_{P A D}$ tree model differs from that of the winter tree, i.e., the $C_{d}$ is also highly dependent on the tree model. It is therefore only meaningful to compare $C_{d}$ values from different studies if the trees are equally well-described. Further, the calibration is likely dependent on the closure model choice. Given these results, it is very difficult to apply $C_{d}$ values derived from one study to a different study.

A more robust way of ensuring that tree representations are comparable in different numerical setups is to estimate the integrated drag and bending moment on the trees, as demonstrated here.

\subsection{The effect of model tree resolutions on numerical simulations}

For dense trees, our analyses show that only a coarse tree model can represent the tree well, i.e. when we increase the realism of the canopy representation, we decrease the accuracy of the numerical prediction. For a sparser tree, we saw no indication of improvement when using a finer tree model.

Possible explanations of these somewhat counter-intuitive effects may be: (i) when resolving the tree to high detail, the resulting model is a mixture of areas with very high values of $A_{P A D}$ and correspondingly low values of $U$, and areas with low $A_{P A D}$ and correspondingly high $U$. When applying the force density term parameterization (Eq. (1)), it is clear that the polarization into these two types of voxels will lead to a lower total force on the tree than a coarser tree models where both $A_{P A D}$ and $U$ remain at a more averaged level. (ii) The formulation of the RANS closure used here is consistent with the flow regimes of grid turbulence and wall-bounded flow as described by Pope (2000). The parameterizations by Sogachev and Panferov (2006) and Sogachev et al. (2012b) were adapted for homogeneous shear flows observed inside tall homogeneous forests. By inferring a high variability in $A_{P A D}$, the situation we try to model is further from the flows the model can be expected to reproduce well and the model should perform poorly. In light of these limitations, and the fact that none of the RANS constants were tuned to improve the fit between wake simulations and observations, the close match indicate that the modelling approach is robust.

The detail required to suitably represent trees in numerical simulations needs to be determined via grid studies such as those presented here in this manuscript. Such studies are also recommended for future simulations focused on heterogeneous forest canopies.

\section{Conclusion}

This study presents first results from a number of new methods, that together allow for an estimate of the impact of a solitary open-

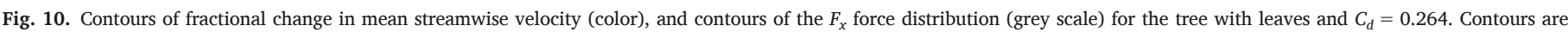

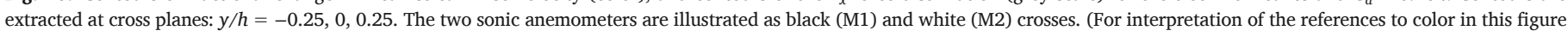
legend, the reader is referred to the web version of this article.) 
grown tree on the wind field. These methods are (i) a detailed tree model based on terrestrial lidar scans (ii) bending moment observations taken at the stem of the tree, and (iii) a numerical model. The effect of the tree was adjusted in the model such that the simulated bending moment matched the observation. The model results were compared with wind observations taken at single-points upwind and downwind of the tree. The prediction of the mean wind speed in the wake of the tree showed good agreement (mean absolute errors $\leq 5 \%$ ) for both the bare and less dense winter tree and the dense summer tree. The model predictions of the turbulent kinetic energy in the wake showed worse agreement with the observations for the winter tree than for the summer tree with leaves.

Especially for the dense summer tree, the level of detail in the tree model had an effect on the total simulated bending moment on the tree. A calibration of the tree model against an observed drag force further showed that the chosen value of the drag coefficient was highly dependent on the grid resolution. Given that the simulations matched the wind observations well and that the numerical setup is relatively inexpensive in terms of computational cost, the presented approach could be adapted for different configurations of multiple trees with the aim to study their collective effect on the wind.

\section{Acknowledgements}

We thank the two anonymous reviewers for their helpful and constructive comments. The technicians and engineers at the DTU Wind Energy Department are acknowledged for raising the masts, instrumentation, installation of data logging. The Independent Research Fund Denmark is acknowledged for the support via The Single Tree Experiment, Grant No. 6111-00121B. The data sets used in the study are available upon request.

\section{References}

Angelou, N., Dellwik, E., Mann, J., 2018. Wind load measurement on an open-grown European oak tree. Forestry(in review).

Ayotte, K.W., Finnigan, J.J., Raupach, M.R., 1999. A second-order closure for neutrally stratified vegetative canopy flows. Bound.-Layer Meteorol. 90 (2), 189-216.

Bai, K., Meneveau, C., Katz, J., 2012. Near-wake turbulent flow structure and mixing length downstream of a fractal tree. Bound.-Layer Meteorol. 143 (2), 285-308.

Béland, M., Widlowski, J.L., Fournier, R.A., 2014. A model for deriving voxel-level tree leaf area density estimates from ground-based LiDAR. Environ. Model. Softw. 51, 184-189. https://doi.org/10.1016/j.envsoft.2013.09.034.

Blackburn, G.R.A., 1997. The growth and mechanical response of trees to wind loading. A thesis submitted to the University of Manchester for the degree of Doctor of Philosophy in the Faculty of Science October 1997, Ph.D. thesis. University of Manchester.

Boudreault, , Bechmann, A., Tarvainen, L., Klemedtsson, L., Shendryk, I., Dellwik, E., 2015. A LiDAR method of canopy structure retrieval for wind modeling of heterogeneous forests. Agric. Forest Meteorol. 201, 86-97.

Boudreault, , Dupont, S., Bechmann, A., Dellwik, E., 2017 mar. How forest inhomogeneities affect the edge flow. Bound.-Layer Meteorol. 162 (3), 375-400. https://doi. org/10.1007/s10546-016-0202-5.

Brunet, Y., Finnigan, J.J., Raupach, M.R., 1994. A wind tunnel study of air flow in waving wheat: single-point velocity statistics. Bound.-Layer Meteorol. 70 (1-2), 95-132.

Dellwik, E., Bingöl, F., Mann, J., 2014. Flow distortion at a dense forest edge. Q. J. Roy. Meteorol. Soc. 140 (679), 676-686.

Dellwik, E., Jensen, N.O., 2000. Internal equilibrium layer growth over forest. Theor. Appl. Climatol. 66, 173-184.

Dwyer, M.J., Patton, E.G., Shaw, R.H., 1997. Turbulent kinetic energy budgets from a large-eddy simulation of airflow above and within a forest canopy. Bound.-Layer Meteorol. 84 (1), 23-43.

Endalew, A.M., Hertog, M., Gebrehiwot, M.G., Baelmans, M., Ramon, H., Nicolaï, B.M., Verboven, P., 2009. Modelling airflow within model plant canopies using an integrated approach. Comput. Electron. Agric. 66 (1), 9-24.

Finnigan, J., 2000. Turbulence in plant canopies. Annu. Rev. Fluid Mech. 32, 519-571. https://doi.org/10.1146/annurev.fluid.32.1.519.

Finnigan, J.J., Shaw, R.H., Patton, E.G., 2009. Turbulence structure above a vegetation canopy. J. Fluid Mech. 637, 387-424

Harman, I.N., Böhm, M., Finnigan, J.J., Hughes, D., 2016. Spatial variability of the flow and turbulence within a model canopy. Bound.-Layer Meteorol. https://doi.org/10. 1007/s10546-016-0150-0.

Irvine, M., Gardiner, B., Hill, M., 1997. The evolution of turbulence across a forest edge. Bound.-Layer Meteorol. 84 (3), 467-496.

Katul, G.G., Mahrt, L., Poggi, D., Sanz, C., 2004. One- and two-equation models for canopy turbulence. Bound.-Layer Meteorol. 113 (1), 81-109.
Lalic, B., Mihailovic, D.T., 2004. An empirical relation describing leaf-area density inside the forest for environmental modeling. J. Appl. Meteorol. 43 (4), 641-645.

Launder, B.E., Spalding, D.B., 1972. Mathematical Models of Turbulence. Academic Press, London, UK.

Leonard, B.P., 1979. A stable and accurate convective modelling procedure based on quadratic upstream interpolation. Comput. Methods Appl. Mech. Eng. 19, 59-98.

Li, Z., Lin, J., Miller, D., 1990. Air flow over and through a forest edge: a steady-state numerical simulation. Bound.-Layer Meteorol. 51, 179-197.

Mann, J., Angelou, N., Arnqvist, J., Callies, D., Cantero, E., Arroyo, R.C., Courtney, M. Cuxart, J., Dellwik, E., Gottschall, J., Ivanell, S., Kühn, P., Lea, G., Matos, J.C., Palma, J.M.L.M., Pauscher, L., Peña, A., Rodrigo, J.S., Söderberg, S., Vasiljevic, N., Rodrigues, C.V., 2017. Complex terrain experiments in the New European Wind Atlas. Phil. Trans. Roy. Soc. A: Math. Phys. Eng. Sci. 375, 20160101.

Michelsen, J.A., 1992. Basis3D - a platform for development of multiblock PDE solvers, Tech. Rep. AFM 92-05. Technical University of Denmark, Lyngby, Denmark.

Moore, J.R., Gardiner, B.A., Blackburn, G.R.A., Brickman, A., Maguire, D.A., 2005. An inexpensive instrument to measure the dynamic response of standing trees to wind loading. Agric. Forest Meteorol. 132 (1-2), 78-83.

Panofsky, H.A., 1973. Tower micrometeorology. In: Haugen, D. (Ed.), Workshop on Micrometeorology. American Met. Soc., pp. 151-174, (Chapter 4).

Patankar, S.V., Spalding, D.B., 1972. A calculation procedure for heat, mass and momentum transfer in three-dimensional parabolic flows. Int. J. Heat Mass Transf. 15, 1787-1806.

Patton, E.G., Sullivan, P.P., Shaw, R.H., Finnigan, J.J., Weil, J.C., 2016. Atmospheric stability influences on coupled boundary layer and canopy turbulence. J. Atmos. Sci. 73 (4), 1621-1647. https://doi.org/10.1175/JAS-D-15-0068.1.

Pinard, J.D.J.-P., Wilson, J.D., 2001. First- and second-order closure models for wind in a plant canopy. J. Appl. Meteorol. 40 (10), 1762-1768.

Poggi, D., Porporato, A., Ridolfi, L., Albertson, J., Katul, G., 2004. The effect of vegetation density on canopy sub-layer turbulence. Bound.-Layer Meteorol. 111 (3), 565-587.

Pope, S., 2000. Turbulent Flows. Cambridge University Press, Cambridge, UK.

Queck, R., Bienert, A., Maas, H.G., Harmansa, S., Goldberg, V., Bernhofer, C., 2012. Wind fields in heterogeneous conifer canopies: parameterisation of momentum absorption using high-resolution 3D vegetation scans. Eur. J. Forest Res. 131 (1), 165-176.

Raupach, M.R., Coppin, P.A., Legg, B., 1986. Experiments on scalar dispersion within a model-plant canopy. Part I: the turbulence structure. Bound.-Layer Meteorol. 35 (1-2), 21-52.

Raynor, G., 1971. Wind and temperature structure in a coniferous forest and a contiguous field. Forest Sci. 17 (3), 351-363.

Réthoré, P.-E., Sørensen, N.N., 2012. A discrete force allocation algorithm for modelling wind turbines in computational fluid dynamics. Wind Energy 15, 915-926.

Réthoré, P.-E., van der Laan, M.P., Troldborg, N., Zahle, F., Sørensen, N.N., 2014. Verification and validation of an actuator disc model. Wind Energy 17, 919-937.

Rhie, C.M., Chow, W.L., 1983. Numerical study of the turbulent flow past an airfoil with trailing edge separation. AIAA J. 21, 1525-1532.

Richards, P.J., Hoxey, R.P., 1993. Appropriate boundary conditions for computational wind engineering models using the k- $\varepsilon$ turbulence model. J. Wind Eng. Ind. Aerodyn. 46 (47), 145-153.

Roy, C.J., 2003. Grid convergence error analysis for mixed-order numerical schemes. Am. Inst. Aeronaut. Astronaut. J. 41 (4), 595-604.

Rudnicki, M., Mitchell, S., Novak, M., 2004. Wind tunnel measurements of crown streamlining and drag relationships for three conifer species. Can. J. For. Res. 34, 666-676.

Schlegel, F., Stiller, J., Bienert, A., Maas, H.G., Queck, R., Bernhofer, C., 2012. Large-eddy simulation of inhomogeneous canopy flows using high resolution terrestrial laser scanning data. Bound.-Layer Meteorol. 142 (2), 223-243.

Segalini, A., Fransson, J.H., Alfredsson, P.H., 2013. Scaling laws in canopy flows: a wind-tunnel analysis. Bound.-Layer Meteorol. 148 (2), 269-283.

Seginer, I., Mulhearn, P., Bradley, E., Finnigan, J., 1976. Techniques for eduction of coherent structures from flow measurements in the atmospheric boundary layer. Bound.-Layer Meteorol. 10, 423-453.

Shaw, R.H., Patton, E.G., 2003. Canopy element influences on resolved- and subgrid-scale energy within a large-eddy simulation. Agric. Forest Meteorol. 115 (1-2), 5-17.

Sogachev, A., Kelly, M., Leclerc, M.Y., 2012. Consistent two-equation closure modelling for atmospheric research: buoyancy and vegetation implementations. Bound.-Layer Meteorol. 145, 307-327.

Sogachev, A., Kelly, M., Leclerc, M.Y., 2012. Consistent two-equation closure modelling for atmospheric research: buoyancy and vegetation implementations. Bound.-Layer Meteorol. 145 (2), 307-327.

Sogachev, A., Panferov, O., 2006. Modification of two-equation models to account for plant drag. Bound.-Layer Meteorol. 121, 229-266.

Sørensen, N.N., 1994. General purpose flow solver applied to flow over hills, Ph.D. thesis Risø National Laboratory, Roskilde, Denmark.

Sørensen, N.N., Bechmann, A., Johansen, J., Myllerup, L., Botha, P., Vinther, S., Nielsen, B.S., 2007. Identification of severe wind conditions using a Reynolds averaged Navier-Stokes solver. J. Phys. Conf. Ser. 75 (012053), 1-13.

Stacey, G.R., Belcher, R.E., Wood, C.J., Gardiner, B.A., 1994. Wind flows and forces in a model spruce forest. Bound.-Layer Meteorol. 69 (3), 311-334.

Vollsinger, S., Mitchell, S.J., Byrne, K.E., Novak, M.D., Rudnicki, M., 2005. Wind tunnel measurements of crown streamlining and drag relationships for several hardwood species. Can. J. Forest Res. 35 (5), 1238-1249.

Wang, H., Takle, E.S., Shen, J.M., 2001. Shelterbelts and windbreaks: mathematical modeling and computer simulations of turbulent flows. Annu. Rev. Fluid Mech. 33, 549-586.

Wilson, J.D., Flesch, T.K., 1999. Wind and remnant tree sway in forest cutblocks. III. A windflow model to diagnose spatial variation. Agric. Forest Meteorol. 93 (4), 259-282.

Zhu, W., van Hour, R., Luznik, L., Kang, H., Katz, J., Meneveau, C., 2006. A comparison of PIV measurements of canopy turbulence performed in the field and in a wind tunnel model. Exp. Fluids 41 (2), 309-318. 